\title{
Incidental Finding of Interrupted Aortic Arch in an Asymptomatic Adult: To Treat or Not to Treat?
}

\author{
Alessandra Sala* and Ottavio Alfieri
}

Department of Cardiovascular and Thoracic Surgery, San Raffaele University Hospital, Milan, Italy

\begin{abstract}
Interrupted aortic arch (IAA) is a congenital anomaly that affects approximately 3 per million live-births. Adult presentation of complete aortic interruption is extremely rare. Surgical repair of IAA is the mainstay of treatment, however beneficial effects of intervention in the adult population are still debated. Late complications of surgical or percutaneous procedures have to be considered when managing asymptomatic adults.
\end{abstract}

Keywords: Aortic arch; Asymptomatic adults; dyspnea

\section{Introduction}

Interrupted aortic arch (IAA) is a congenital anomaly that affects approximately 3 per million live-births, which is characterized as loss of continuity either of the aortic arch or at the level of the aortic isthmus. This case study deals with a 59-year-old female with interrupted aortic arch. Diagnosis was associated to combined stenosis and regurgitation of the aortic valve and the patient underwent surgery with replacement of the aortic valve with a mechanical prosthesis.

\section{Case Presentation}

A 59-year-old female with past medical history of breast cancer, treated with quadrantectomy, lymphadenectomy and chemotherapy, and a normal to-term pregnancy, presented to our department due to mild-to-moderate dyspnea.

A couple of years' prior she had an incidental finding of interruption of the aortic arch (IAA), and aneurysm of a right intercostal artery. At the time of diagnosis, no treatment had been proposed for IAA, however percutaneous exclusion, with two DBS balloons, was performed at the origin of the arterial aneurysm.

The patient reports a very active life-style (swims 1 hour, 4 to 5 times/week) and a slight progression of symptoms in the past months. Upon presentation the woman appeared healthy, fit, with a normally developed upper body in contrast to fairly minute lower limbs. Initial examination revealed moderate hypertension measured on both upper limbs (brachial blood pressure (BP) $150 / 75 \mathrm{mmHg}$ ) and a pressure difference measured on lower limbs (BP 100/60 mmHg), with delayed and reduce femoral pulses. Furthermore, pounding intercostal pulses could be easily felt bilaterally. Heart auscultation revealed a systolic murmur on the right parasternal second intercostal space. Physical examination of all other systems was found to be normal. The patient was on triple anti-hypertensive medications: amlodipine $(10 \mathrm{mg} /$ day $)$, bisoprolol ( $2.5 \mathrm{mg} /$ day) and ramipril (10 mg/day).

Chest X-ray (CXR) was performed, which showed typical rib notching bilaterally [1], compatible with prominent collateral circulation secondary to IAA, and a slightly enlarged cardiac silhouette. Transesophageal (TEE) echocardiography was later performed to assess heart and valve function. TEE showed hypertrophy and dilation of the left ventricle, with normal left ventricular ejection fraction (EF 65\%). The aortic valve appeared bicuspid (antero-posterior classification), with fibro-calcific degeneration resulting in moderate-to-severe aortic insufficiency (vena contracta (VC) 5.5 to $6 \mathrm{~mm}$ ) and moderate associated stenosis (maximal gradient of $64 \mathrm{mmHg}$, mean gradient of $38 \mathrm{mmHg}$ ). Trace mitral regurgitation was also detected.
In order to better assess the complete aortic coarctation a cardiac magnetic resonance angiography was performed [2]. Images confirmed complete interruption of the aortic arch, distal to the left subclavian artery, and prominent collateral circulation (Figures 1A and 1B).

A diagnosis of combined stenosis and regurgitation of the aortic valve was made and the patient underwent surgery with replacement of the aortic valve with a mechanical prosthesis (St. Jude Medical n.19). Prior to surgery, during patient workup, transcatheter treatment for aortic valve replacement was also taken into consideration; however due to anatomical aspects, prominent intercostal circulation and tortuosity of the aortic branches, percutaneous procedures were rejected.

The patient was discharged on postoperative day 5 without major complications. At 1-year follow-up the patient was in good clinical conditions, asymptomatic for dyspnea, and went back to her normal life-style and daily exercises. Blood pressure control was greatly improved, with a modification of anti-hypertensive medications' regimen: amlodipine was suspended and slight decrease in ACE inhibitor dose was implemented.

\section{Discussion}

Interrupted aortic arch (IAA) is a congenital anomaly defined as loss of continuity either of the aortic arch or at the level of the aortic isthmus; it affects approximately 3 per million live-births [3]. Adult presentation of complete aortic interruption is extremely rare. IAA differs from aortic coarctation by the degree of stenosis of the thoracic aorta. According to the location of the interruption of the aortic arch, IAA can be classified into three categories: type A, being the most common and accounting for $79 \%$ of cases, occurs distal to the left subclavian artery; type B occurring between the left carotid and left subclavian arteries, and type $\mathrm{C}$ presenting between the innominate artery and the left carotid artery [4]. Further anomalies are commonly associated with IAA: the most common is bicuspid aortic valve seen

*Corresponding author: Dr. Alessandra Sala, Department of Cardiovascular and Thoracic Surgery, San Raffaele University Hospital, Milan, Italy, Tel: +39 0291751 543; E-mail: a.sala1@studenti.unisr.it

Received August 13, 2017; Accepted September 22, 2017; Published September 26, 2017

Citation: Sala A, Alfieri O (2017) Incidental Finding of Interrupted Aortic Arch in an Asymptomatic Adult: To Treat or Not to Treat? J Cardiovasc Dis Diagn 5: 293. doi: 10.4172/2329-9517.1000293

Copyright: (c) 2017 Sala A, et al. This is an open-access article distributed under the terms of the Creative Commons Attribution License, which permits unrestricted use, distribution, and reproduction in any medium, provided the original author and source are credited. 

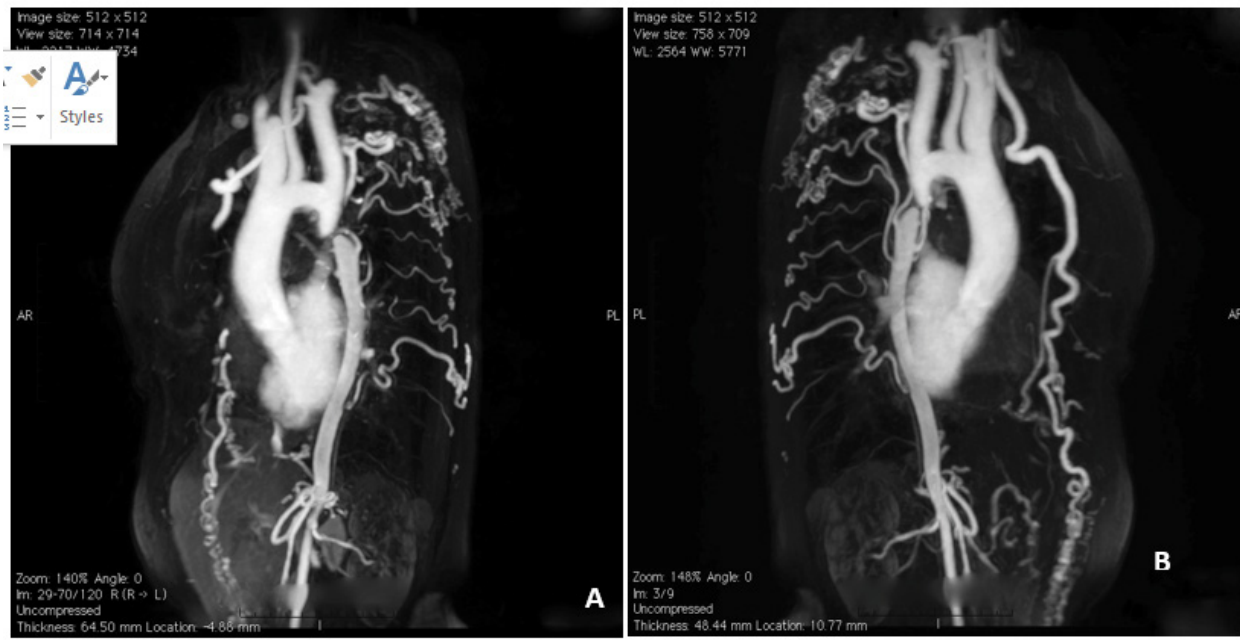

Figure 1: Cardiac magnetic resonance angiography image showing A) Interruption of the aortic arch distal to the left subclavian artery and B) Prominent intercostal collateral circulation.

in $50 \%$ of cases. Others include, atrial septal defects, ventricular septal defects, patent ductus arteriosus, and intracranial aneurysms, particularly in the region of the Circle of Willis [5].

Surgical repair of aortic coarctation and IAA is the mainstay of treatment, and several surgical techniques have been used: end-toend anastomosis, end-to-side anastomosis, or bypass grafting. In the current era, advances in the percutaneous treatment of such defect have also been made and described [6,7]. However, while clinical, both short and long-term, benefits of surgical treatment in the infant population are well documented, great debate and inconsistency of results are reported for the adult population. The major improvement is described as a significant reduction in hypertension, and as a consequence a decreased overall risk for cardiovascular events and complications $[8,9]$. Nonetheless, surgery is associated with long-term complications that need to be thoroughly assessed when planning management of such patients. Matter-of-factly, repair does not necessarily indicate cure of cardiovascular abnormalities. Re-coarctation can occur in up to $40 \%$ of treated individuals; among others also aortic aneurysm and dissection, cerebrovascular accidents, late systemic hypertension and overall survival [10]. All of the above listed factors being even more concerning in adult patients. Systemic hypertension can occur after successful repair, and among risk factors for development are older age at the time of surgery and a higher baseline blood pressure $[11,12]$. Indeed, poor resolution of hypertension was more common among patients above the age of 30 at the time of repair $[13,14]$. Furthermore, perioperative death is reported to be significantly higher in patients undergoing surgical repair past the third decade of life [15].

\section{Conclusion}

Therefore, the natural history of IAA is strongly dependent on development of systemic hypertension and survival to adulthood is per se impressive, even more so in an asymptomatic fashion. This, together with clinical implications of repair at an older age should warrant merit when planning the best patient-tailored treatment [16,17]; medical management is feasible, and may in fact be the best approach in this subset of patients.

\section{References}

1. John AS, Schaff HV, Drew T, Warnes CA, Ammash N (2011) Adult presentation of interrupted aortic arch: Case presentation and review of the medical literature. Congenit Heart Dis 6: 269-275.
2. Shepherd B, Abbas A, Mcparland P, Fitzsimmons S, Shambrook J, et al. (2015) $\mathrm{MRI}$ in adult patients with aortic coarctation: Diagnosis and follow-up. Clin Radiol 70: 433-445.

3. Weinberg $P(2008)$ Aortic arch anomalies. In: Allen H, Driscoll D, Shaddy $\mathrm{R}$, Feltes $\mathrm{T}$ (eds). Moss and Adams' heart disease in infants, children, and adolescents. Philadelphia, Pa: Lippincott Williams \& Wilkins, USA. pp. 730-760.

4. Celoria GC, Patton RB (1959) Congenital absence of the aortic arch. Am Heart J 58: 407-413.

5. Connolly HM, Huston III J, Brown Jr RD, Warnes CA, Ammash NM, et al. (2003) Intracranial aneurysms in patients with coarctation of the aorta. Mayo Clin Proc 78: 1491-1499.

6. Kische S, Ancona GD, Ince H (2017) Percutaneous treatment of adult aortic coarctation with multiple intrathoracic aneurysms. J Vasc Surg 66: 265.

7. Luijendijk P, Bouma B, Groenink M, Boekholdt M, Hazekamp M, et al. (2012 Surgical versus percutaneous treatment of aortic coarctation: New standards in an era of transcatheter repair. Expert Rev Cardiovasc Ther 10: 1517-1531.

8. Cardoso G, Abecassis M, Anjos R, Marques M, Koukoulis G, et al. (2014) Aortic coarctation repair in the adult. J Card Surg 29: 512-518.

9. Karl TR (2007) Surgery is the best treatment for primary coarctation in the majority of cases. J Cardiovasc Med 8: 50-56.

10. Vriend JWJ, Mulder BJM (2005) Late complications in patients after repair of aortic coarctation: Implications for management. Int J Cardiol 101: 399-406.

11. Brouwer RMHJ, Erasmus ME, Ebels T, Eijgelaar A (1994) Influence of age on survival, late hypertension, and recoarctation in elective aortic coarctation repair. J Thorac Cardiovasc Surg 108: 525-531.

12. Canniffe C, Ou P, Walsh K, Bonnet D, Celermajer D (2013) Hypertension after repair of aortic coarctation- A systematic review. Int J Cardiol 167: 2456-2461.

13. Bhat A, Neelakandhan K, Unnikrishnan M, Rathore R, Mohan Singh M, et al. (2001) Fate of hypertension after repair of coarctation of the aorta in adults. Br J Surg 88: 536-538.

14. Olley $P$ (1979) The late results of coarctectomy performed after one year of age. In: Tucker B, Lindesmith $G$ (eds). First clinical conference on congenital heart disease. New York: Grune and Stratton. USA. pp.159-166.

15. Cohen M, Fuster V, Steele PM, Driscoll D, Mcgoon DC (1989) Coarctation of the aorta. Long-term follow-up and prediction of outcome after surgical correction. Circulation 80: 840-845.

16. Zivelonghi C, Pighi M, Perandini S, Vassanelli C, Ribichini F (2014) Asymptomatic severe aortic coarctation at old age. Int J Cardiol 173: e56-e57.

17. Khan AN, Carter W, Mousa AY (2015) Medical management of aortic coarctation is feasible and durable in selected patients: A case report and literature review. WV Med J 111: 18-21. 